MATEC Web of Conferences 19,01028 (2014)

DOI: $10.1051 /$ matecconf/ 20141901028

CC Owned by the authors, published by EDP Sciences, 2014

\title{
Increase resource power electronics module on the physics of failure method
}

\author{
Evgeny V. Kravchenko a, Geniy V. Kuznetsov \\ Tomsk Polytechnic University, 634050, Tomsk, Russia, Lenin av., 30
}

\begin{abstract}
A new approach to improving resource devices for power electronics. The numerical analysis of non-uniform temperature field of power semiconductor devices. A comparison of the intensities of the failure of a power unit with the real thermal regime of the device under conditions of natural convection and obtained by using statistical data analysis. The integrated assessment of reliability based on the methods of physics failures. The necessity of taking into account the actual non-stationary temperature fields to improve the reliability of the forecast operating life of power semiconductor devices.
\end{abstract}

\section{Introduction}

During operation of power semiconductor devices, a number of factors that severely limit their life [1]. Most of these devices are designed to work with the utmost ambient temperature of up to $318 \mathrm{~K}$. But also, the temperature field of power devices themselves is essentially nonstationary, and extremes of temperature (T) on the product can reach 20-30 K [2]. That leads to an increase in the failure rate of devices in more than twofold at the higher temperature semiconductor device for every $10 \mathrm{~K}$ (in the operating range $\mathrm{T}$ ) [3]. The effect of reducing the operational reliability (life) with increasing $\mathrm{T}$ is observed not only in the power semiconductor devices, but, for example, when using transformers. Established [4] that the lifetime of the latter is reduced by an average of $2.5 \%$ with an increase in ambient temperature of $10 \mathrm{~K}$. It can be concluded that the resource efficiency power electronics devices depend strongly on the thermal conditions of their work.

Predicting the reliability of any power system, as a rule, is carried out on the basis of a priori information $[5,6]$. There are different approaches depending on the type of system. For large, such as electricity, using methods based on the numerical values of the electric remote nodes [5], on the analysis of the mode of operation [6]. However, the reliability of the operation of any system depends on the operating life of the "small-size" element (electric-connection section of the cable, the power semiconductor device, transformer, etc.) emitted as a result of the decomposition into components. Is it known a method of predicting the residual life of electric-compounds [7]. As the resource parameter takes the temperature of the hottest point of contact of the compound [7]. The main considerations in evaluating the reliability of the semiconductor switch thyristor group composed of a strong phase rotation device taken MTBF (MTBF - Mean time before failure) and the first warning off [8]. For predicting the reliability of power transformers used methods of probabilistic modeling [9], including models based on Markov processes [10].

\footnotetext{
${ }^{a}$ Corresponding author: e-mail: kevatp@tpu.ru
} 
Another approach for predicting the reliability of the power system, based on the physics of failure (POF - Physics of Failure) analysis [11-18]. The reliability of the power system is viewed from its components, taking into account the aging [11] in conjunction with the effect of adverse weather conditions [12]. Indicators of reliability of the power system are determined by using a mathematical model of degradation of cable products. [13] Assess the residual life of isolation of electrical devices were obtained [14] on the basis of the generalized polarization index and the experimental data on the change in the intensity of partial discharge in the aging process of the dielectric [15]. Reliability indices of a number of electrical devices are defined taking into account the degradation of the polymer components [16-18]. But the analysis of the physics of failure is usually carried out without taking into account the spatial distribution of temperature change in the time of the objects [11-16].

Proposed in this paper an approach to the analysis of thermal modes of power semiconductor devices can be the basis of methods of POF. The use of POF will improve resource efficiency of semiconductor devices. At the same time, using this method will expand the range of application and can significantly increase energy efficiency. If in Russia we reach the world average uses of power semiconductors, the economy will save $12 \div 15 \%$ of the total electricity generated [1]. In the following, the methods based on the physics of failure, may be an important component of the concept PDfR (PDfR - Probabilistic Design for Reliability) [19] and DRM (DRM - Dynamic Reliability Management) [20].

The aim of this work - the analysis of integrated indicators of reliability of power semiconductor devices based on the numerical simulation of unsteady non-uniform temperature field in the presence of several local heat sources located in the natural convection at different operating temperatures.

\section{Analysis of the thermal mode of the power semiconductor device}

Modern power devices can be formally divided into two groups. The first group of devices used primarily for converting very large capacities, include diodes and thyristors. The second groups of devices that are used in a range of small and medium capacity represent the field (MOSFET - metaloxide-semiconductor field effect transistor) and bipolar field-effect transistors (IGBT - Insulated-gate bipolar transistor).

Analysis of warm mode was based on typical power electronics relatively simple device - power diode module with a transition temperature see point $\mathrm{T}_{\text {iunct }}=125^{\circ} \mathrm{C}$. (Fig. 1 ).

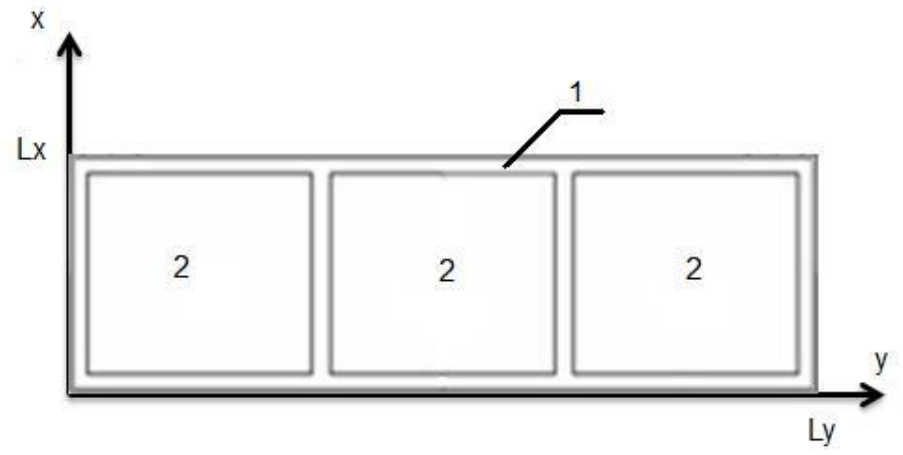

Figure 1. The geometry of solutions (1,2 - area with different thermal characteristics).

Numerical simulation of the temperature field in an inhomogeneous plate with dimensions in the $\mathrm{x}$ and $y$ are equal $\mathrm{L}_{\mathrm{x}}$ and $\mathrm{L}_{\mathrm{y}}$.

where $\mathrm{x}, \mathrm{y}$ - coordinates.

$$
x \in\left[0 ; L_{x}\right], y \in\left[0 ; L_{y}\right]
$$


It was assumed that the model (plate) includes areas with different thermal characteristics. In three areas (area 2, Fig. 1.) Is a local heat given intensity Q. At the edges of the plate boundary conditions of the kind III (mixed heat transfer).

Key assumptions used in the formulation of the problem.

1 Thermal characteristics of the materials does not depend on temperature.

2 Thermal contact at the boundaries between the areas $(1,2)$ is considered ideal.

In such context, the task comes to the solution of non-stationary thermal conductivity equation:

$$
C(x, y) \rho(x, y) \frac{\partial T}{\partial t}=\frac{\partial}{\partial x}\left(\lambda(x, y) \frac{\partial T}{\partial x}\right)+\frac{\partial}{\partial y}\left(\lambda(x, y) \frac{\partial T}{\partial y}\right)+\frac{Q(t, x, y)}{S h}+\frac{\alpha(T)\left(T_{\text {ext }}-T\right)}{h}+\frac{\varepsilon_{\text {ref }} \sigma\left(T_{\text {ext }}^{4}-T^{4}\right)}{h}
$$

Where: C-heat capacity; $\rho$ - density; T-temperature; $t$ - time; $\lambda$ - thermal conductivity coefficient; $Q$ - heat source; S-source area; $h$ - plate thickness; $\alpha$ - convective heat transfer coefficient of the surface; $\mathrm{T}_{\text {ext }}$ - environment temperature; $\sigma$ - Stefan-Boltzmann constant; $\varepsilon_{\text {ref }}-$ the emissivity of the surface of the plate and the environment.

A method for solving a differential equation similar to that described in the article [21, 22].

\section{Reliability indicators of power semiconductor device}

The analysis of the reliability indices of the diode module two mathematical models such as-Arrhenius [3] and a multiplicative model [23] were selected. The mathematical multiplicative model [23] of the reliability evaluation diode module is shown below

$$
\lambda_{e}=\lambda_{b} \cdot \mathrm{K}_{p} \cdot \mathrm{K}_{f} \cdot \mathrm{K}_{k} \cdot \mathrm{K}_{e},
$$

where: $\lambda_{b}$-base failure rate of the power unit; $K_{p}$ - coefficient of mode, depending on the temperature and the electric load; $\mathrm{K}_{f}$-functional specificity mode device coefficient; $\mathrm{K}_{k}$-level of quality coefficient; $\mathrm{K}_{e}-$ stiffness conditions.

It is important to note that the basic failure rate used in the mathematical models of the type (3) In determining the reliability indices $\left(\lambda_{b}\right)$ are given for the temperature of $25^{\circ} \mathrm{C}$ [23] and do not include, for example, the spatial inhomogeneity of temperature fields inside products, and for him outside.

Therefore, the analysis of reliability indices of a typical power electronics device (diode module) is also carried out on the basis of a mathematical model, for which $\mathrm{T}$ is one of the most important factors [3]. In accordance with the Arrhenius model failure rate depends exponentially on the temperature [3]:

$$
\lambda_{\mathrm{A}}(T)=C \cdot \exp \left(\frac{-E}{k T}\right)
$$

Where: C-constant, E-activation energy, k-Boltzmann constant.

The temperature used according to (4), was determined from the results of the two-dimensional non-stationary solutions of the heat equation (2) with the appropriate boundary conditions.

\section{Results and discussion}

The characteristic form of the temperature field simulation object (diode module) at ambient temperature $\mathrm{T}=25^{\circ} \mathrm{C}$ at time $\mathrm{t}=900 \mathrm{c}$ is shown in Figure 2 


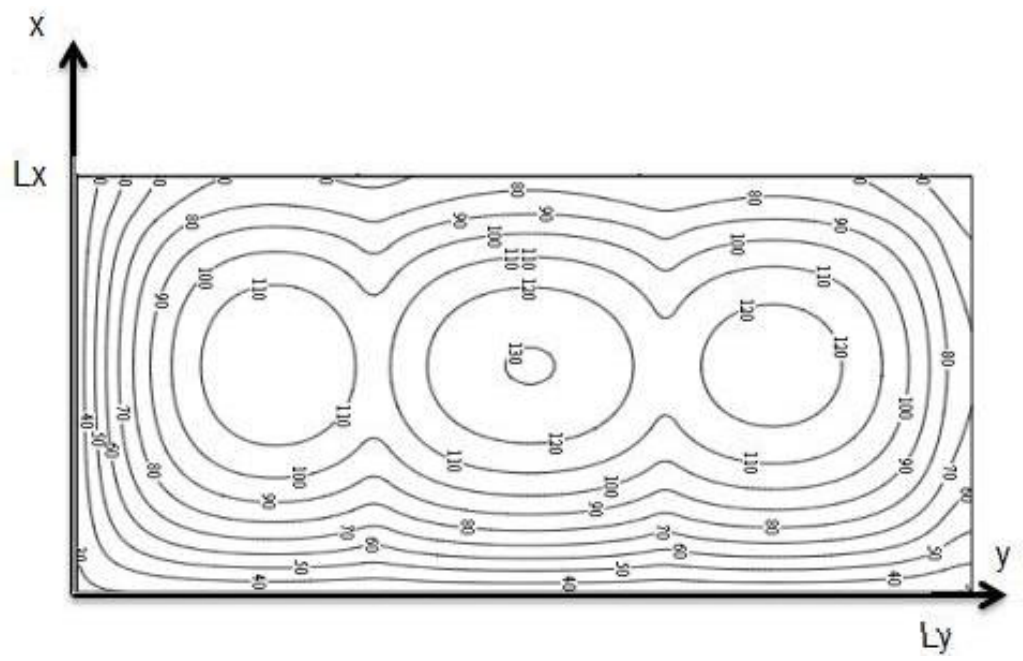

Figure 2. Temperature field of the simulated object (the temperature in degrees Celsius).

Shown in Fig. 2 the temperature field of power semiconductor device is typical for the given initial conditions and the operation mode. Analysis heat flow through the surface of the module (Fig. 1) shows that the temperature of the heated region (Fig. 2) at $5-10 \mathrm{~K}$ higher than see point $\mathrm{T}_{\text {junct }}$. Temperature field of the device under consideration is essentially non-uniform and is characterized by significant gradients of $\mathrm{T}$.

As an example, considered two on-off cycles at various intervals (see the table).

Table. Time ON-OFF cycles (in seconds)

\begin{tabular}{|l|l|l|l|l|}
\hline & ON & OFF & ON & OFF \\
\hline Example 1 & $0-399$ & $400-599$ & $600-999$ & $1000-1200$ \\
\hline Example 2 & $0-299$ & $300-599$ & $600-899$ & $900-1200$ \\
\hline
\end{tabular}

Analysis of resource power device using the Arrhenius model is advisable for the average $\left(\mathrm{T}_{\mathrm{av}}\right)$ and maximum $\left(\mathrm{T}_{\max }\right)$ temperatures of the object (Fig. 3).

Increase in ambient temperature leads to a $\mathrm{T}$ for adequate growth model for the two options. Thus, temperature control operation of the power module of approximately $10 \mathrm{~K}$ below the second embodiment.

The results of numerical modeling of indicators of reliability (failure rate) power semiconductors are shown in Fig. 3. The behavior of the failure rate $\lambda_{A}(T)$ reflects not only the significant differences in the estimates of reliability models (3) and (4), but also a high degree of dependence of the Arrhenius model prediction (curves 1 and 2 in Fig. 3) of the estimated (accepted) temperature.

Dependency analysis presented in Figure 4 indicates that the numerical value calculated by the Arrhenius model (4), a 5-fold higher in Tmax relative to the time $\mathrm{T}_{\mathrm{av}}$ of $1000 \mathrm{~s}$. and an ambient temperature of $300 \mathrm{~K}$ (see Fig. 4a). The failure rate of the power semiconductor device, as determined by the model (4), for the Tav (curve 2 in Fig. 3), 29 times more than for the multiplicative model (3) at $\mathrm{t}=1000 \mathrm{~s}$. Reducing the time of switching cycles (example №2 on Fig.3b) increases the operational reliability (life) is almost a factor of 2 hands (Fig. 4b). 
With increasing ambient temperature increases the failure rate of the power semiconductor device. Dependency analysis on Figure 3c and 3d shows that variants №1 reliability index below about twice and a little more than twice for the variant №2 at maximum failure rates.

Significant differences in the reliability of the estimates due to several reasons:

- $\quad$ significant variation of the temperature field of the simulated device power electronics (due to local sources of heat);

- $\quad$ the base failure rate $\left(\lambda_{\mathrm{b}}\right.$ in Equation 3) used in the evaluation $\lambda_{\mathrm{e}}$, defined for $\mathrm{T}_{\mathrm{ext}}=300$ $\mathrm{K}$;

- with increasing Text is a decrease of the intensity of convective heat transfer, causing even greater heterogeneity of temperature fields with a corresponding increase of the maximum and average temperatures on the device.
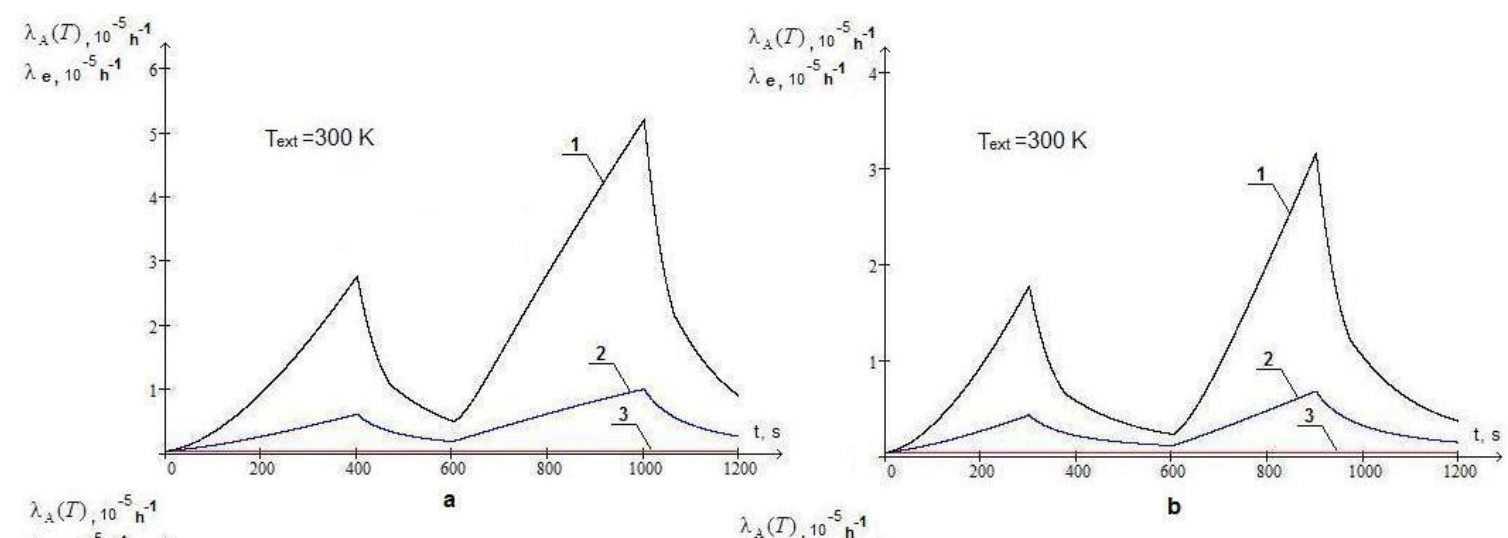

$\lambda_{\mathrm{e}, 10^{-5} \mathrm{~h}}{ }^{-1}$
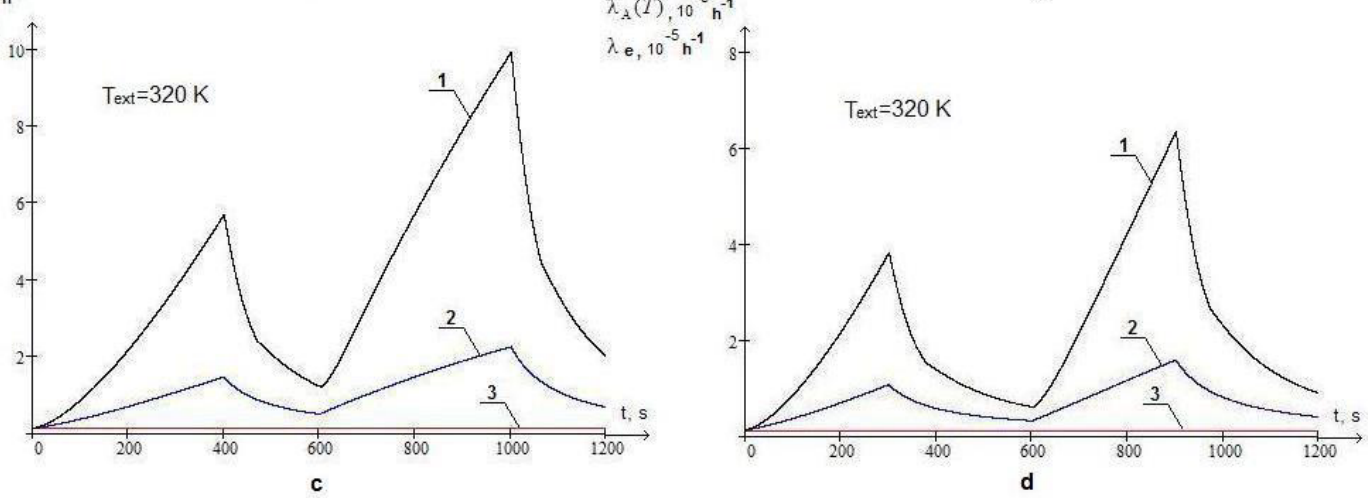

Figure 3. The dependence of the failure rate versus time for various cycles of ON-OFF. (1 - Arrhenius model $\left(\mathrm{T}_{\max }\right), 2$ - Arrhenius model $\left(\mathrm{T}_{\mathrm{av}}\right), 3$ - multiplicative model $\left(\mathrm{T}_{\text {const }}\right)$.

\section{Conclusion}

Forecasting of reliability of power semiconductor devices should be carried out on the basis of analysis of the real non-stationary inhomogeneous thermal mode of the device.

The proposed mathematical apparatus allows you to manage the resource of power semiconductor devices. 
Also, on the basis of the new approach may predict the reliability of power devices in applications such as locomotives, elevator, tram and subway, for which there is no statistical information. That will increase energy efficiency in their respective fields.

The reported study was supported by the Grant of the Russian Scientific Fund (project № 14-3900003).

\section{References}

1. I.V. Grehov, Bulletin of the Russian Academy of Sciences, 2, (2008)

2. G.V. Kuznetsov, M.A. Sheremet, Russian Microelectronics, 5, (2009)

3. A.A. Borisov, V.M. Gorbachev, G.D. Kartashow, M.N. Martynov, S.F. Prytkov, Foreign electronics, 5, (2000)

4. A.N. Nazarychev, D.A. Andreev, Pedro Antonio, E.A. Kireev, Bulletin of the ISPU, 3, (2009)

5. Yu. A. Fokin, Ya. N. Osipov, Electrical Technology Russia, 5, (2010)

6. V.V. Afanasev, V.M. Kozhevnikov, Reability, 3, (2012)

7. V.V. Izmailov, M.V Novoselova, Russian Electrical Engineering, 5, (2009)

8. M.A. Novikov, P.A. Rashitov, Russian Electrical Engineering, 12, (2013)

9. V.M. Saltykov, L.M. Suleimanova, Electromechanics, 6, (2007)

10. M.Sefidgaran, M. Mirzaie, A. Ebrahimzadeh, Int.J. of Elect.Pow.\&Ener.Sys., 35, (2012)

11. W. Li, IEEE Trans Power Syst, 17, (2002)

12. M.H.J. Bollen, IEEE Trans Ind Appl., 37, (2001)

13. M. Stötzel, M. Zdrallek, W.H. Wellssow, IEEE Proc Gen Transm Distrib., 48, (2001)

14. F.R. Ismagilov, D.V. Maksudov, Russian Electrical Engineering, 2, (2012)

15. E.V. Zenova, V.A. Chernyshov, Bulletin of the MEI, 2, (2011)

16. D.A. Silva, E.C.M. Costa, J.L. Franco, M. Antonionni, R.C. Jesus, S.R. Abreu, K. Lahti, L.H.I. Mei, J. Pissolato, Int.J. of Elect.Pow.\&Ener.Sys., 53, (2013)

17. G.V. Kuznetsov, E.V. Kravchenko, Elektromagnitnye Volny i Elektronnye Systemy, 3 (2014)

18. G.V. Kuznetsov, E.V. Kravchenko, Journal of Engineering Physics and Thermophysics, 80 (5), (2007)

19. E. Suhir, Microelectronics Reliability, 52, (2012)

20. Y. Wang, M. Enachescu, S.D. Cotofana, L. Microelectronics Reliability, 52, (2012)

21. S.F. Prytkov, V.M. Gorbachev, Handbook «Reliability of radioelements» (Moscow, 2012)

22. E.V. Kravchenko, G.V. Kuznetsov, EPJ Web of Conferences, 76, (2014)

23. G.V. Kuznetsov, E.V. Kravchenko, Elektromagnitnye Volny i Elektronnye Systemy, 10 (1112), (2005) 